\title{
Experimental research on English vowel errors analysis
}

\author{
Qiuhua Huang* \\ Key Laboratory of National Language Intelligent Processing, Northwest University for Nationalities, Gansu, \\ Lanzhou, China
}

\begin{abstract}
Our paper analyzed relevant acoustic parameters of people's speech samples and the results that compared with English standard pronunciation with methods of experimental phonetics by phonetic analysis software and statistical analysis software. Then we summarized phonetic pronunciation errors of college students through the analysis of English pronunciation of vowels, we found that college students' English pronunciation are easy occur tongue position and lip shape errors during pronounce vowels. Based on analysis of pronunciation errors, we put forward targeted voice training for college students' English pronunciation, eventually increased the students learning interest, and improved the teaching of English phonetics.
\end{abstract}

Keywords: experimental research; vowels; acoustic analysis; errors analysis

\section{INTRODUCTION}

Recently, with the rapid development of experimental phonetics, the second language acquisition research about English pronunciation is gradually emerging in China. There are great developments in theory and practice of the research. Some domestic scholars through analyze pronunciation of Chinese English learners, and made a comparison with speaker whose mother tongue is English. Results showed that the deficiencies and errors of Chinese English learners in spoken language, then analyzed vowel errors, and put forward the method and theory about improving the rate of correct pronunciation. However, due to the restrictions of objective conditions and research methods, the research in domestic about English phonetic acquisition is rare. Most of the research still stays in the traditional western linguistic theories and research methods are supervisor analysis, questionnaire investigation and case discussion, which lack of operability and verification. Research process lacks of systematic experimental design and scientific experimental analysis. Therefore, the research results lack of quantitative data analysis and conclusion lacks of objective evidences. At present, English phonetic teaching and learning in China are still holding the traditional explanation, imitating and training, there is

\footnotetext{
*Corresponding author: 1195875797@qq.com
}

no analysis of the errors and problem, the study efficiency and the enthusiasm of the learners are not positive.

English pronunciation of Chinese college students is a difficult issue in English teaching, although each school sets a well-targeted curriculum, the problem still exists. In this paper, we used methods of experimental phonetics and speech analysis software to study, which not only can observe sonograms and analyze data objectively, but also can find out the errors in pronunciation. Firstly, analyze the errors. Secondly, find out problems. Finally, aiming at the problems, we give the corresponding solutions. What's more, provide reference methods for Chinese college students' English phonetic learning. During analyzing the problem, we first clarified our targets that specify the vowel of college students' English pronunciation. The research methods mainly used speech analysis software Audition and Praat. We analyze parameters and finally find out the errors that can easy to occur in Chinese students' English learning. We concluded the problems and provide correct guidance for learners, and improve the pronunciation of English speech.

\section{EXPERIMENTAL METHODS}

Our research begins with two dimensions--segmental 
phonemes and supra-segmental phonemes of the English pronunciation. Moreover, we used experimental phonetics and speech analysis software, such as audition, Praat and Multi-speech 3700. We analyzed the English phonetics of 30 sophomore non-English Major of Northwest University for Nationalities, including 15 boys and 15 girls. In addition, in order to check the error analysis and comparative in college students' pronunciation, we also record 4 western teachers' pronunciation, including 2 males and 2 females who are from London where pronunciation is standard RP.

\subsection{Corpus collection}

Before the voice recording, we need to design audio text according to the research objective. Text design mainly is segmental phonemes of English pronunciation, namely the vowels in the English, including 12 monophthongs and 8 diphthongs. The sound recording with the software Audition, as shown in Figure 1. Each speaker requires being relaxed and nature, and the pronunciation should be clarity. The speed should not be too fast; every text is read three times, each text has 1-3 seconds pauses, and each speaker's speech file is stored separately. Recording used the single track with 16 bits, the sampling rate is $16 \mathrm{kHz}$, and all voice saved as WAV format. The recording place is a professional studio, with a complete suite type, audio equipment, and the sound insulation effect is good.

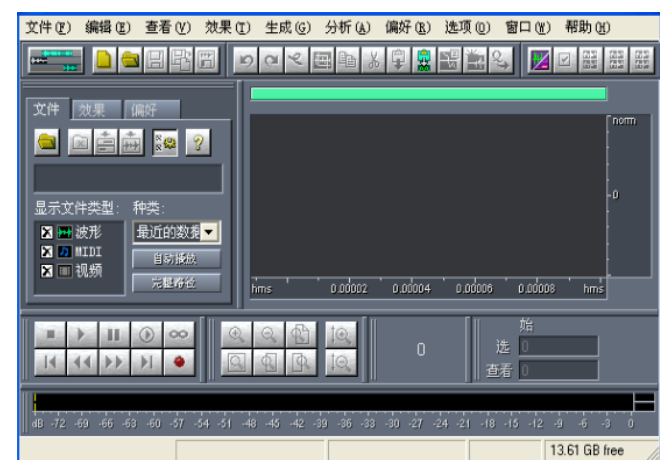

Figure 1. Audition recording interface

\subsection{Analysis method}

The paper mainly involves monophthongs, diphthongs consonants and long sentences. The methods are as follows:

The analysis objects of monophthongs are formants and duration. We used the Praat software to extract the first three formants of the vowel F1, F2, F3, respectively, which are normalized by the formula $\mathrm{z}=$ (Fn-MEANn)/Sn. The purpose of the normalization is to reduce the differences of individual physiological as far as possible, and then the normalized data are processed by the statistical software SPSS. The duration analysis is through the statistics of the length of single vowel' pronunciation. Finally, we made a comparative study on statistical data of college students and foreign teachers, and summarize the acquisition of monophthongs of the college students.

The main analysis of the diphthongs is duration, which includes total duration of diphthong, and stable segment duration and transition section duration of two phonemes; and roportion of single phoneme duration and total duration.

\section{ERROR ANALYSIS OF ENGLISH VOWELS}

There are 20 vowels in English, including 12 monophthongs and 8 diphthongs. Vocal folds vibration and oral airflow is unimpeded when vowel sounds; the changes of back-front of tongue position and lips rounded-non-rounded, which adjust speech respectively, and then the acoustic characteristics of each vowel are different.

\subsection{Error Analysis of Monophthongs pronunciations}

Compared with Chinese, there are long vowels and short vowels in English. The difference of phoneme duration is not only in pronunciation' duration, but also in distinguish meaning. In addition, the long vowel and short vowel are relative duration; Generally speaking, the vowel duration is inequality in different words. This part mainly analyzes the formants and duration of college students and foreign teachers, and then compares the data. The results of experiments are as follow.

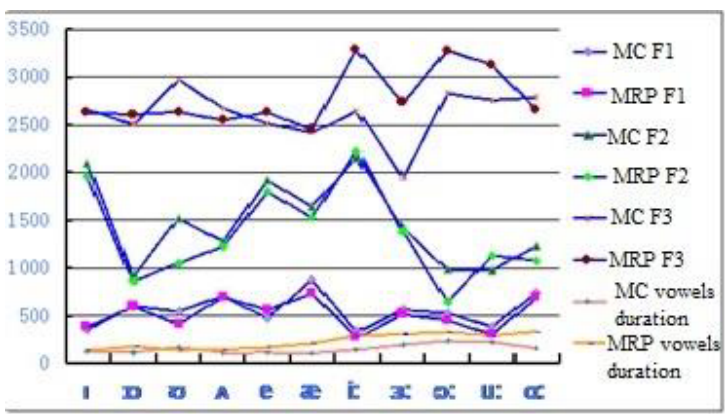

Figure 2. Acoustic analysis of monophthongs of male

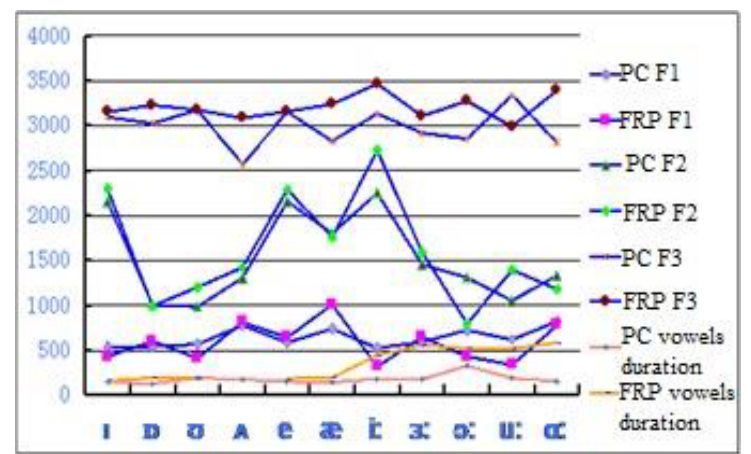

Figure 3. Acoustic analysis of monophthongs of female

In Figure 2 and Figure 3, MC is the male speaker, 
and MRP is RP pronunciation of the male foreign teachers. FC is the female speaker, and FRP is RP pronunciation of the female foreign teachers. From the results, we can find that there is a gender difference in the formants and duration of vowels. In Figure 2, there is little difference between male college students and male foreign teachers in the first formants value, especially vowel $/ \mathrm{i}: /$. The pronunciation of $/ \mathrm{\rho}: /, / \mathrm{u}$ : /is better, and the pronunciation of $/ \mho /, / \mathrm{e} /, / \mathfrak{a} /$ is worse. It shows that male college students have a good command of height of tongue position; while there is great difference in F2 and F3, which indicates that poor grasp of back-front of tongue position, and the tongue is too rolling. In Figure3, compared with the pronunciation of male, female's mastery of height tongue position is worse, but there is little difference between female students and foreign teachers in the vowel F1, while the difference of F2、F3 is larger. By comparison, we found that college students have a good command of height of tongue position while poor grasp of back-front of tongue position; Among them, tongue position of $/ \mathrm{o}: /$, /a:/ is front, and tongue position of $/ \mathrm{I} /$, $/ \Lambda /, / \mathrm{e} /, / 3: /$ is back. The universal phenomenon is that tongue of male and female is too rolling in pronounces.

By analyzing duration and comparing two groups' data, we found that college students have a good grasp of short vowel duration but poor grasp of long vowel duration. The universal phenomenon is that long vowel sounds too short in pronounce, which related to the vowels which cannot be distinguished in Mandarin Chinese. And the duration of vowels in Mandarin Chinese has no significant difference.

\subsection{Error Analysis of Diphthongs pronunciations}

The most important feature of diphthongs is glide, which slides from the first vowel to the second vowel, and moves the tongue from one position to the next; while mouth changes in the process of sliding. The first vowel pronunciation is usually stronger than the later one. Two vowel phonemes are more independence and tongue position transit slowly in English Diphthongs. Tongue position and lip position changes significantly, and then each vowel pronunciation is clear. There are 8 diphthongs in English, which including 5 closing diphthongs, such as /eI/, /aI/, /oI/,

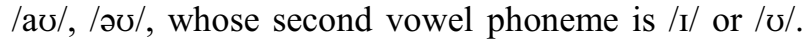
The lip is from open to close and tongue is from low to high while pronunciation. Another pronunciation is cacuminal, such as /ı/, /eə/, /\%ə/, whose second vowel phoneme is $/ \partial /$. The lip and tongue position tends to central vowel gradually during pronunciation. These two kinds of diphthongs have a common feature that the first vowel pronunciation louder than the second vowels, and the duration of first vowel is longer than the second vowel.

We analyze the total duration of diphthongs and stable section duration of single vowel and transition section duration between two vowels, as well as the proportion of total duration. The results of experiment are showed as follow.

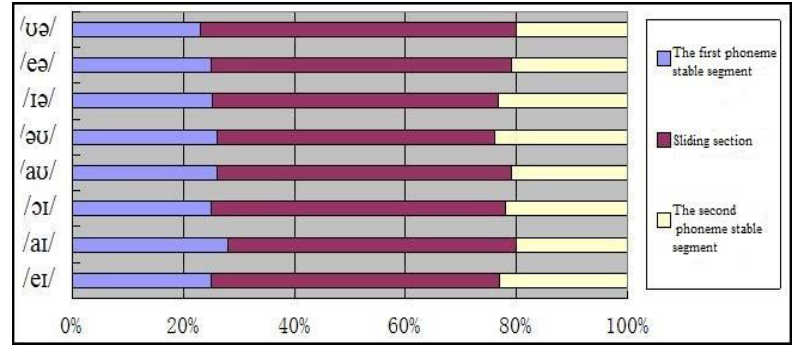

Figure 4. Acoustic analysis of diphthongs duration of male foreign teachers

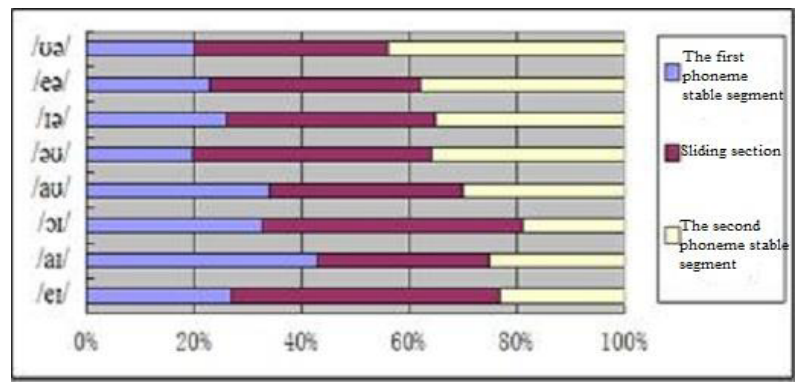

Figure 5. Acoustic analysis of diphthongs duration of male college students

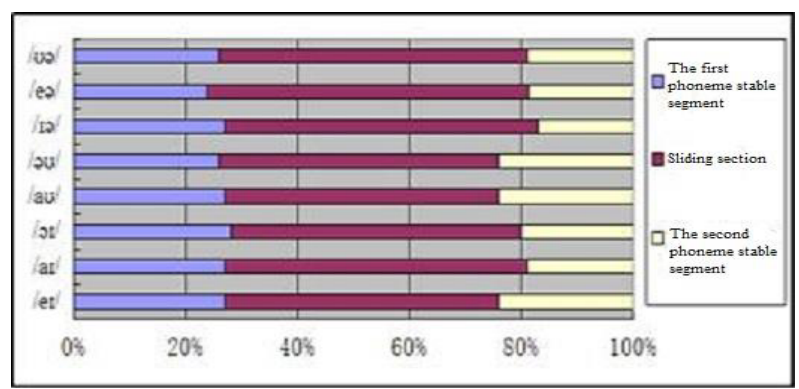

Figure 6. Acoustic analysis of diphthongs duration of female foreign teachers

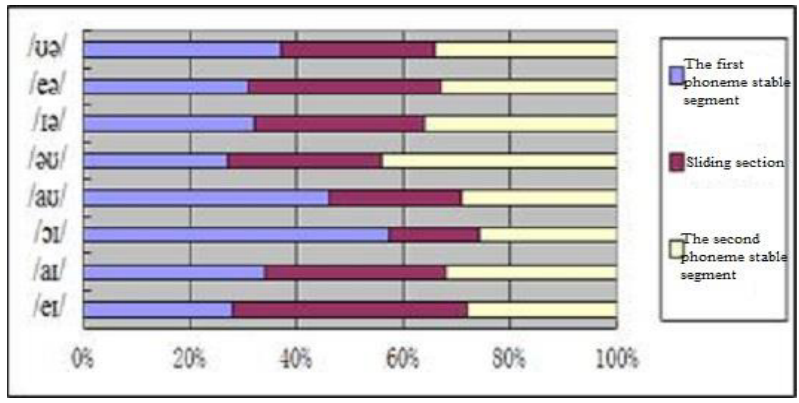

Figure 7. Acoustic analysis of diphthongs duration of female college students

Through the data analysis, we firstly found that the male college students' total duration of diphthongs is less than foreign teachers'. The female college students' total duration of closing diphthongs is longer 
than foreign teachers', except the /oI/. The duration of three diphthongs' which tend to cacuminal, is shorter than foreign teachers. Secondly, the features are not obvious in sliding process of college students' diphthongs. The transition between two vowel phonemes is not obvious, and the transition section duration is shorter significantly than foreign teacher's pronunciation. Thirdly, there are differences between college students and foreign teachers in the duration of diphthongs pronunciation. In foreign teacher's diphthongs pronunciation, the first vowel is heavier than the latter vowel. Moreover, the first vowel duration is longer than the second vowels. But in the pronunciation of the college students, the second vowel duration is longer than the first vowel, and the first vowel is lighter than the latter vowel.

In order to further analyze the diphthongs acoustic features, we used Praat to analyze diphthongs sonogram, and observe the formats changes of diphthongs, which are shown in Figure 8-11.

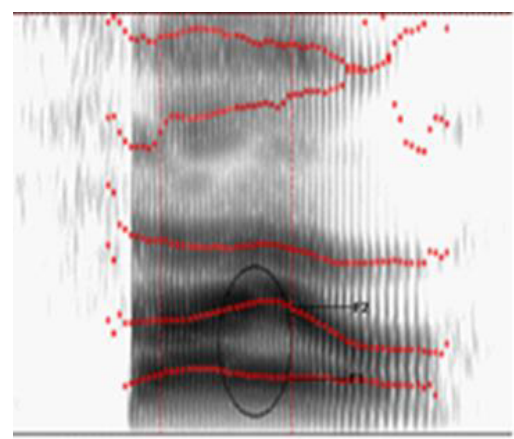

Figure 8 . File /farl/ pronunciation of male college students

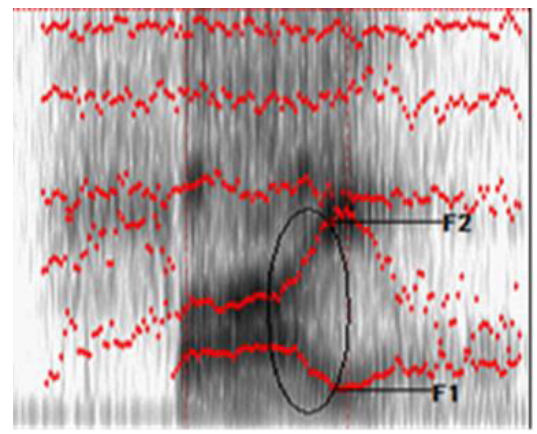

Figure 9. File /farl/ pronunciation of male foreign teachers

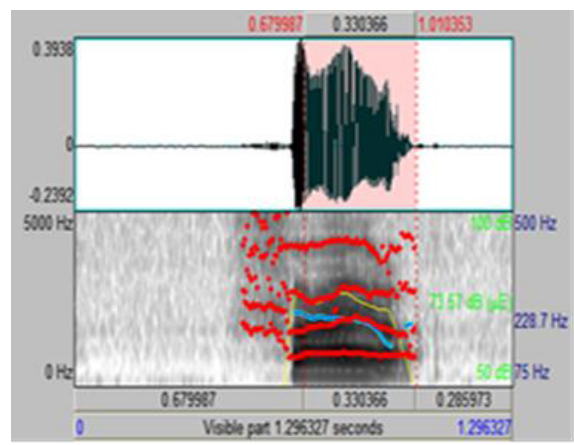

Figure 10. Fare /fea/ pronunciation of female college students

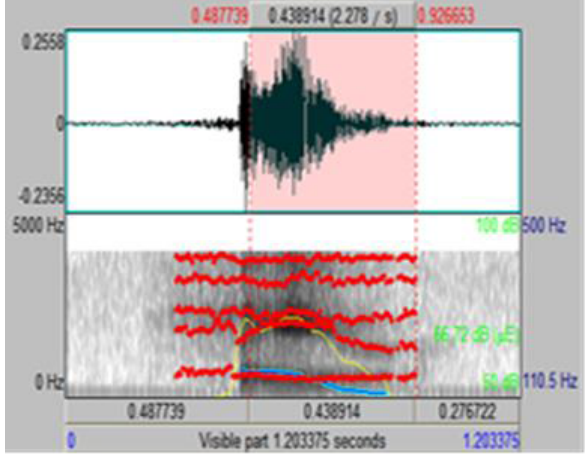

Figure 11. Fare /fea/ pronunciation of female foreign teachers

There is an obvious difference between monophthongs and diphthongs in formats. The format has a rise and fall when pronounced from one vowel to another one. In the figures above, there are obvious transitions between F1 and F2 of two foreign teachers' pronunciation. In the Figure 9, because of tongue position from high to low and back to front in $/ \mathrm{a} /, / \mathrm{I} /$ pronunciation, F1 has a transition from high to low, and F2 has a transition from low to high. In the Figure 11 , tongue position is also from high to low and back to front in /e/, //2/ pronunciation, so F1 has transition from high to low, and F2 has transition from back to front. Furthermore, the transition is significant. Compared with the foreign teacher's pronunciation, Figure8 and Figure 10 are college students' pronunciation, whose F1 and F2 transition of monophthongs pronunciation is short, as well as the format curves are smooth, which indicates that single vowel pronunciation is not clear. There is no significant transition between two vowels, and tongue position change is not flexible enough when native college students pronounced.

\section{SUMMARIES}

The vowels acoustic analysis shows that pronunciation is more accurate if the pronunciation parameters are close to foreign teachers'. In this paper, analyze data of vowel formant and duration to sum up the errors in the pronunciation of non-English major students. Focus on the following points:

1) The errors of tongue position in pronounced. The main error is high-low and back-front of tongue position, which has great difference with foreign teacher's pronunciation in the grasp of back-front of tongue position. The change of tongue position of college students showed that the degree of front and back is not enough.

2) Cacuminal is too heavy. Cacuminal problem of female college students is heavier, and long vowels tend to cacuminal vowel when pronounce.

3) Duration error. The duration of long vowel and diphthongs is short in native college students pronounce. Especially in diphthongs, the transition du- 
ration between two vowels is generally short, and the first vowel is shorter than the latter vowel.

This paper analyzed the problem of English vowels pronunciation of college students by experimental Phonetics methods. It provides a quantitative method for the research of English pronunciation teaching, and used scientific data to find language problems. This paper analyzed the vowels, so that we can design consonant and rhythm in the future research. Meanwhile, we increase the number of speaker, and the research objects which extend from college students to different levels learner in the crowd, thereby we will increase the universal significance of the research.

\section{ACKNOWLEDGEMENT}

The successful of this paper was subsidized by Central Universities Fundamental Research Funds for the project: Mandarin Nasal Research based on Acoustic and Physiological Analysis (31920150035); Postgraduates' Scientific Research (Practice) Innovation
Projects in Northwest University for Nationalities (Yxm2014136)

\section{REFERENCES}

[1] Ladefoged, Peter. 2003. Phonetic Data Analysis: An Introduction to Fieldwork and Instrumental Techniques. Malden: Blackwell.

[2] Ladefoged, P. 1982. A Course in Phonetics. New York: Harcourt, Brace, Jovanovich.

[3] Nathan, S. 1987. On second-language acquisition of voiced stops. Journal of Phonetics, (15): 313-322.

[4] Chiba, Kajiyama. 1958. Vowel: Its Nature and Structure. Tokyo, MA: The Phonetic Society of Japan.

[5] Corder, S.P. 1967. The significance of learners' errors International Review of Applied Linguistics, 05.

[6] P. Ladefoged, Peter. 1995. Elements of Acoustic Phonetics (2nd Ed.). Chicago: University of Chicago Press.

[7] Lightbown, Patsy M. and Spada, Nina. 2002. How Languages are Learned. Shanghai: Shanghai Foreign Language Education Press.

[8] G. Taylor. 1986. Error and Explanations. Applied linguistics, pp.144-166 